\title{
DIGITAL TRANSFORMATION IN THE HUNGARIAN BANKING INDUSTRY - EXPERIENCES WITH DESIGN THINKING
}

\author{
PÉTER FEHÉR ${ }^{1}$ - KRISZTIÁN VARGA ${ }^{2}$ \\ ${ }^{1}$ Institute of Information Technology, Corvinus University of Budapest, Hungary \\ Email: peter.feher@uni-corvinus.hu \\ ${ }^{2}$ Institute of Information Technology, Corvinus University of Budapest, Hungary \\ Email: krisztian.varga@uni-corvinus.hu
}

The study examines the possibilities of the digital transformation of the Hungarian banking industry through the "One Week Sprint" method, derived from general design thinking methodology. In our research, we cooperated with two domestic banks and focused on real estate related opportunities and SME offerings. The methodological focus was on how to use customer journeys and personas for supporting digital efforts, as design thinking places a great emphasis on these elements. The paper has two goals: 1) present the findings of this innovative project with the two banks using design thinking; 2) describe our experience with customer journeys and personas in consumer- and corporate-facing innovation projects in the two banks. To our knowledge, there is no practical experience in the literature regarding the usage of these tools. We found that the usage of customer journeys and personas are much easier and evident if the project tries to develop consumer products or solutions. If the solutions are for corporate use, personas lose the added value of empathy (without the human connection) and the creation of customer journeys needs deeper experience from consultants.

Keywords: digital transformation, design thinking, One-Week Sprint, banking industry, customer journey, persona

JEL-code: G21 


\section{INTRODUCTION}

The traditional financial industry is facing several new challenges due to rapid technological advancement. While the financial industry (banks, insurance and investments companies, intermediaries, etc.) has traditionally been a strong user of technologies, these efforts mostly concentrated on back-office systems. The new challenge is coming from the customer side: the role of customer experience, especially digital customer experience, has increased. However, this field was not really a strength of the financial industry. In this paper, we concentrate on the banking industry, and use design thinking as a methodology which may assist banks in answering the challenges.

We first provide an overview of the challenges of the banking industry in general and in Hungary in Section 2. In Section 3, we introduce design thinking, which can be a solution to enhancing the customer experience and answering the challenges outlined in Section 2. We put a greater emphasis on the literature focusing on customer journey mapping and the usage of personas in Section 3. In Section 4, we will demonstrate the added value and the challenges faced when using these tools in our design thinking projects with banks.

\section{CHALLENGES OF BANKING INDUSTRY}

In case of banks, the status quo is challenged by several factors. Startup companies using technology are finding niche markets, and can achieve higher efficiency than traditional banks. These startups (fintech companies) offer strong digital customer experience.

Deloitte's recent global digital banking survey across 17 countries showed that banking consumers have a stronger emotional connection to technology brands like Apple, Amazon, and Google than to their banks. Some of these companies' ability to blend experiences from the physical and digital worlds is considered a good model for banks (Ross - Srinivas 2018). Technology giants, like Google, Apple, Samsung, Amazon, Alibaba have wide customer bases, and already act as intermediaries; in the field of payments, they can be alternate service providers. They have both the technological capacity and easy access to their customer base, which facilitates the introduction of new financial services.

The growing influence of fintech companies and non-banks seems an accepted fact by now. Investment in online lending platforms by both startups and incumbents (for example, Finn by JPMorgan Chase) is also significant. While it is unclear how many fintech companies will apply for the Office of the Comptroller of the Currency's (OCC) new banking charter, this seems a sign of maturity in 
the industry as fintech companies become part of the mainstream banking system (Deloitte, 2019).

The legal environment is changing, especially in the European Union. To motivate cooperation between players in the financial industry and help spread digital solutions, regulators introduced several new opportunities: e.g. the eIDAS directive, which regulates electronic identification and trust services for electronic transactions; or the PSD2 directive which compels banks to share their customer data with third parties (of course in a strictly regulated way). While these regulations open opportunities for new entrants, traditional banks are forced to comply with these regulations and open their ecosystem. In Europe, PSD2 and the open banking standard are having the intended effects - spurring innovation and creating a more level playing field. But incumbents have not been caught flat-footed, and have responded well to the challenge. Encouragingly, open banking is catching on in other parts of the world, despite the lack of a regulatory mandate. In the United States, banks were expected to test the waters in 2019 (Boms 2018).

Across the globe, the retail banking industry is fast embracing a mobile-centric customer experience. Investments in mobile technologies have increased meaningfully with Asia Pacific leading the world in the rapid adoption of digital banking due to consumers' constantly evolving demands (Temenos Group 2018). In response, banks are deploying a mix of strategies to stay ahead in the game, among others higher technology spending on channel improvement, including branches, ATMs, call centers, and digital banking (Figure 1).

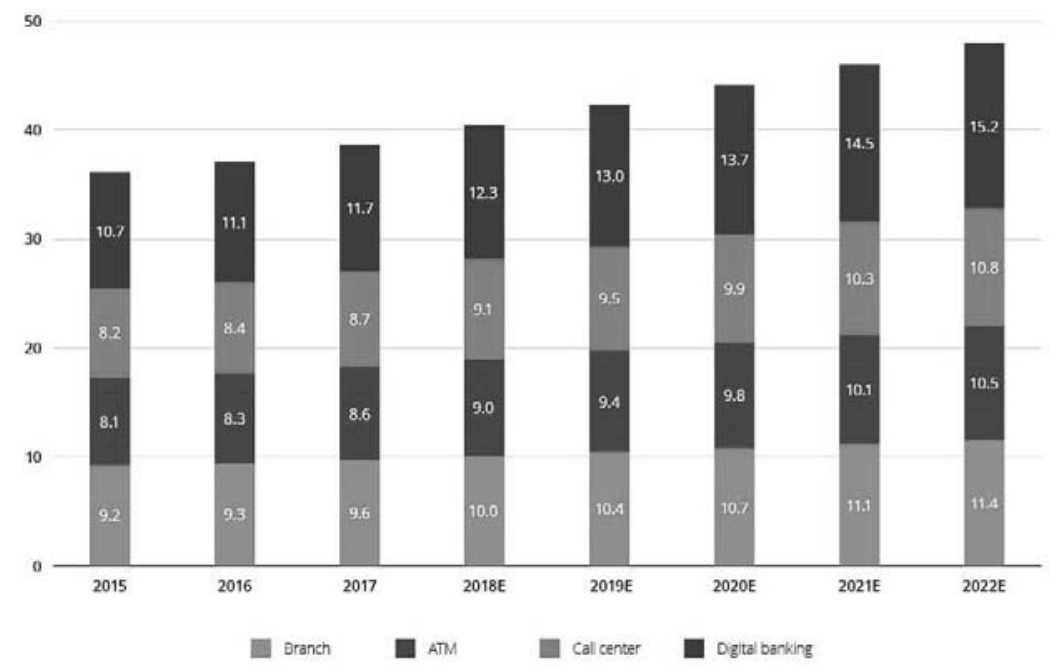

Figure 1. Retail banks' ICT spending on channel improvement, 2015-2022, in billion USD. 
Banks can decide to resist the above-mentioned changes, neglect digital channels, and drive their business in a traditional way, concentrating on the personal customer experience. They can develop modern flagship branches, but the risk of losing market to digital challengers is eminent. Ghose et al. (2016) analyzed the digital transformation of several industries in order to predict the pace of changes in the financial industry. Their analysis predicts a maximum ten-year long period based on past experiences, but the time required to be digitally disrupted as industry is decreasing. Therefore, a significant shift towards digital models is expected in the next five years on more advanced, and seven years in developing financial markets.

But accepting the unstoppable digitalization of the industry, traditional banks can adapt themselves to the new requirements in several ways (Blackstad - Allen 2016). Banks can decide to compete with their challengers via digital developments, applying even a focused niche digital strategy, or a general digital strategy. With a successful general digital strategy, banks can maintain a competitive advantage over their niche challengers, provide a more complex offering. Another possible way is for banks to develop their competitive advantage by integrating other areas, so they become aggregators or ecosystem providers. This could include a fintech integration platform, or even a wider range of non-financial services (e.g. movie tickets, digital parking services, books, etc.). Banks may also become service providers: with digital advancement, banks can decide not to compete on the market anymore, but offer white-label digital products for additional players, offering the background infrastructure and the management of the service infrastructure. Third parties can brand these services as their own product, and even tailor the user experience. The final opportunity is to become an infrastructure provider. Choosing this, banks can decide not to compete with digital challengers, but use their strong experience in back-office infrastructure, which is yet required for banking transactions. They can focus on their existing strength and position themselves as professional financial infrastructure providers.

However, the importance of the branch in attracting and retaining customers, contrary to conventional wisdom, should remain. According to a recent Deloitte survey, branches will continue to have value, especially with greater digital enablement (Ross - Srinivas 2018).

Selecting either digitally related options, if banks are heading toward digital development, they have to compete with their digital challengers, and their efforts require front-office, customer-facing developments. The need to create a seamless omnichannel experience to improve customer experience (CX) has been around for some time. With the available technologies, retail banks are expected to make significant progress in operating in a fluid, post-channel world. The challengers already have the advantage of applying customer centric development solutions, in a very efficient way. 
In our previous research, we have identified the main challenges of the Hungarian banking industry. Our main findings can be grouped into three main areas (Fehér - Varga 2017b).

The first area is the changing role of branches: customers articulated a number of problems related to branches. We found that no one likes to go to bank branches, especially not the younger generation. The traditional functionality of bank branches was to serve as the central point of customer relations. However, visiting a branch may be seen as a drag for customers, or worse, as a source of frustration. From the bank's side, the reduction in the number of customer visits should motivate branches to take advantage of these rare opportunities, improve customer relationships and try to sell new products and services using their personal presence. From the customers' side, the branch visits are considered as a task with no significant added value, so they would like to do it as fast as possible. All the things that prevent this (waiting, administration time, listening to offers) are considered an annoyance.

The second area is digital, omni-channel services. Empowering customers to manage their issues in an online channel seems to be an obvious solution for many problems. At the same time, managing issues outside the branch (via telephone, online or mobile) leads to challenges that would have been easy to handle in the branch itself, such as an inadequate supply of information, a lack of consultation and the functional limitations of the different platforms. Regarding the non-branch channels, the most frequently expressed counter-argument is the issue of security: whether the data of the customer is secure, how the customer is reassured that they are communicating with the bank itself, what guarantees that the customer's order is really executed, etc.

The third area is "Products and services". Regarding administration in branches, customers highlighted the lack of transparency in the bureaucracy of banking, and that there is a lot of paperwork with all issues. The administration of loans and investments turned out to be the most affected by the problem. The rules and the processes laid down by banks are too complex, complicated and incomprehensive for customers. Customers typically get information from these rules and processes from clerks, and sometimes different clerks give different information for the same issue. It is also a common customer complaint that the rules seem to be articulated in a way that the customer cannot understand them.

From the bank's side, ensuring customer experience is becoming more challenging, but if a bank can implement a customer facing approach such as design thinking, they can benefit from it very fast. But how can a bank know what their existing and prospective customers see as the most desirable areas for development? How can they compete with fintech startups, which concentrate on narrow customer needs? Developing solutions without a clear vision of customer expec- 
tations is not just a waste of money for the banks, but also a missed development opportunity which creates a lag behind the challengers. To support rapid digital advancement, the traditional innovation methodologies are challenged, too.

\section{DESIGN THINKING}

To answer the digital challenges, banks need a new approach for digital developments. An approach that design digital services based on real customer expectations offer great digital user experience, and are competitive and agile in the sense of using resources.

Design thinking is a collective label of methodologies, and its general process includes the following steps (Gioia 2011: 39; Dam - Siang 2017):

1. Define: defining the scope, problem and challenges, understanding constrains

2. Explore: explore the target area, context and stakeholders

3. Interpret: process the explored insights and define the problem to be solved

4. Ideate: collect, then evaluate multiple solutions

5. Prototype: develop initial prototypes to illustrate the solution

6. Iterate: test the prototypes, even in multiple cycles to enhance the idea and to select the most suitable solution

7. Implement: develop the product or service

8. Enhance: keep up with the product, provide supper, analyze data and plan further developments (restart the cycle)

Research shows the importance of customer experience: to win a new customer is 6-7 times more expensive than to keep an existing one, whilst loyal customers are worth up to 10 times as much as their first purchase (White House Office of Customer Affairs, quoted by Software AG 2017). To know a company's customers, and the challenges they are facing, design thinking recommends using customer journey mapping and analysis with personas.

\subsection{Customer journey mapping and analysis}

Customer journey mapping and analysis is the process of tracking and describing all the experiences that customers have as they encounter a service, taking into account not only what happens to them, but also their responses. The resulting maps are powerful, visual devices that graphically document customer interactions and experiences with all the customer actions. According to Touchpoint 
Dashboard (2014) a customer journey map must include customer segments or personas, the journey itself (customer actions) and the touchpoints, quantitative and qualitative customer data (thoughts and feelings).

At first, the context must be clarified: what is the journey itself, who are the customer personas. The journey will be unique to all personas, at least in terms of its details. The second step is to identify the stages: these are the customer actions. Based on the literature (SAP Hybrids 2016; Oracle 2015), the general stages of the customer journey are:

- Awareness: At this early stage in the journey, customers are passive. External or internal events can make the customer realize that they have a need.

- Discovery: Customers are evaluating options at a high level. Their research is generally light and focused on their need.

- Interest: Customers enter this phase when actively seeking to build a comprehensive list of viable solutions. Their research goal is creating a solid short list of solutions that merit deeper consideration (some models call this the discovery and interest to research phase).

- Consideration (selection): Customers are aggressively seeking information to determine their best option.

- Action (purchase or onboarding): Having decided to continue with the purchase, they are now moving to execute the transaction itself.

- Use (service): Equipped with the new purchase, customers assess whether the solution and vendor are satisfactory.

- Advocacy: Depending on whether the experience has been positive or negative, a customer will have concrete feelings about the solution and will want to share these.

The third step is to identify the customer touchpoints and map them along the journey. The interesting questions here are: At which points does the customer interact with the organization? Which channels do they come through? Following this, the customer's thoughts and feelings at each touchpoint should be described, based on qualitative and quantitative data. After all of these comes the moment of truth. Key interactions should be identified that may provide opportunity for intervention. The main question is whether there are any significant gaps in the customer journey.

Used well, customer journey mapping and analysis can reveal opportunities for improvement and unmet, real customer needs, acting as a strategic tool to ensure every interaction with the customer is as positive as it can be (HM Government 2017). Customer journey mapping and analysis can uncover key moments of truth for customers and areas for cost and efficiency savings (Lawton 2016). 


\subsection{Usage of personas}

Cooper (1999: 123) defines personas as: "A precise description of our user and what he wishes to accomplish." Calde, Goodwin and Reimann (2002) give a more detailed definition: "User models, or personas, are fictional, detailed archetypical characters that represent distinct groupings of behaviors, goals and motivations observed and identified during the research phase." A persona is thus a fictive person that represents a larger number of users with similar characteristics, expectations, and motivations. Personas surrogate real users in the analysis of a situation and in the design process of a solution. The usage of personas allows common understanding across the entire analyst and design team. Personas should not be too complex, so designers can internalize them. Personas should describe typical usage scenarios, but they must not be an average user in all of their characteristics.

Criticism of personas falls into three general categories: analysis of the underlying logic (because personas are fictional, they have no clear relationship to real customer data and therefore cannot be considered scientific), concerns about practical implementation, and empirical results (Köhler 2001; Chapman Milham 2006; Rönkkö 2005). Another problem with using personas is that some organizations are not ready for the methodology. Creating hypothetical users with real names, stories and personalities may seem unserious and whimsical to some people, teams or organizations.

\section{USING DESIGN THINKING IN THE BANKING INDUSTRY}

In this section we give an overview of our tailor-made methodology, the "One Week Sprint". We review our project experiences with two Hungarian banks. Our goal is to show our practical experiences with the customer journey mapping and analysis with personas; and with design thinking in general.

\subsection{The applied methodology: the "One Week Sprint"}

Using the common design thinking methodologies and the experiences of successful design thinking projects, we have developed the so-called "One Week Sprint" methodology. This method consists of five phases (one day for each), outlining banking problem areas and solutions, focusing on a specific area. The phases are the following (see also Figure 2): 
1. Exploration: here the goal is to get an overview and common understanding of the area of research, with interviewing or inspecting the customers or users.

2. Interpretation: this phase transforms experiences from the field trip and stories of customers into meaningful insights.

3. Ideation: generating many ideas. At this phase, we do not take feasibility and sustainability into account.

4. Experimentation: picking ideas and bringing them to life via rapid prototyping. The goal is to have rapidly as much customer feedback as possible.

5. Evolution: the development of the final concept of the chosen idea.

We have successfully used this methodology in several innovation projects. The industries and areas of these projects were banking, FMCG, investment, insurance and smart city. The duration of these projects were $5 \times 1$ days, organized in one working week or in 5 weeks. Detailed methodology can be found in a previous paper (Fehér - Varga 2017a).

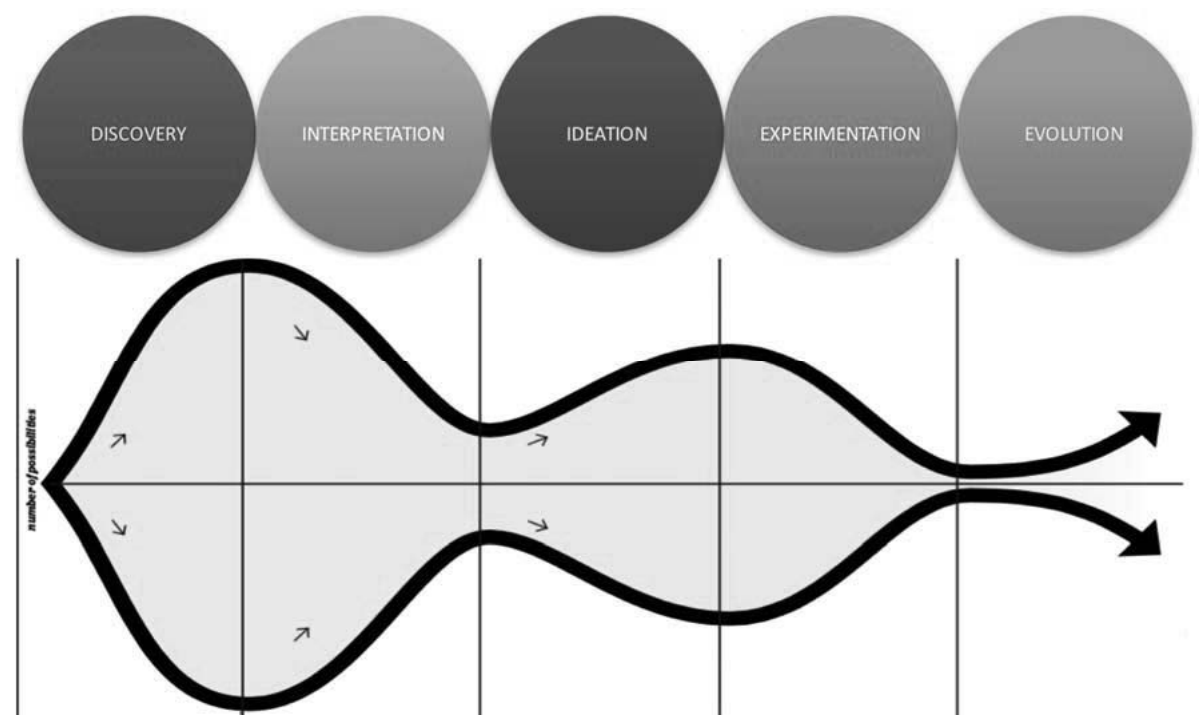

Figure 2. Overview of the "One Week Sprint"

Source: authors 


\subsection{General overview of the two cases}

Bank1 is one of the largest banks in Hungary. It provides financial services through several subsidiaries. It is important that the bank has traditional finance services, but one of its subsidiaries offers real estate services. It has its digital lab, where they are working together with their startup partners to develop financial services for the future. Bank2 is a smaller player than Bank1, but it is very active in digital transformation. It has its own digital lab as well, with an academy program for fintech companies.

We have chosen these two banks because we had previous projects with them, where we already tested the One Week Sprint. Due to this, they knew what to expect, and it was easier to start working with them. The previous projects with these banks were about consumer products, so in this project, we offered to focus on products for corporate customers. So we made an initializing interview with the two banks we were working with, to find the focus area. Bank1 named property loan and mortgages as the area where they want to reach a bigger customer base. Bank2 had a looser focus: they wanted to know what kind of services they should add to their SME bank accounts.

\subsection{The phases of the One Week Sprint in the two cases}

After the focus areas were set, we started the five-day sprint process. In the exploration phase we collected all data available online from the current practices and offers, then conducted a field visit, where we interviewed customers to find out who they are, and how they interact with the banks. This will be the base of the customer journey mapping and analysis with the proper personas, since in most cases, personas are synthesized from data collected from interviews with users (Caroll 1995).

The interviews were different in the two banks. In Bank1, where the focus was on real-estate and mortgages, we asked only customers who managed something related to these topics. In Bank2, we spoke with as much corporate customers as possible, focusing on the SME sector. The questions for the interviews are in Table 1.

In design thinking, stories are an important part of getting to know the customers. That is the reason why the questions are a bit general, and most of them ask the interviewee to describe a specific practice of experience.

In the one-week sprint, data for personas are collected in the Exploration phase, and the personas are formed in the interpretation phase. In the interpretation phase, we aimed to understand the opinions of clients, while analyzing domestic and international banking practice. We have created the personas and the general customer journey, which was tailored for all the personas, based on 
Table 1. Interview questions

\begin{tabular}{|c|c|}
\hline Bank1 & Bank2 \\
\hline $\begin{array}{l}\text { Describe yourself in a few sentences. } \\
\text { Describe the process of purchasing real estate. } \\
\text { Where are you now in the process? } \\
\text { Which phase was a pain point? } \\
\text { In which phase do you think the bank should } \\
\text { be involved? } \\
\text { Tell us a story about your purchase and the } \\
\text { bank. }\end{array}$ & $\begin{array}{l}\text { Describe yourself and your company in a few } \\
\text { sentences. } \\
\text { How often do you come to the branch? } \\
\text { What kind of issues do you have to manage } \\
\text { with the bank? } \\
\text { Can you think about any company related issue } \\
\text { in which the bank should be involved? } \\
\text { Tell us a story about your bank. }\end{array}$ \\
\hline
\end{tabular}

Source: authors

the data, not the steps. In this way, we were able to identify the real problem areas that needed to be solved. As a result, we were able to focus not only on the area of real estate finance in Bank1, which is traditionally a banking product, but also on consumer demand, whether it comes to searching for real estate, conscious purchases, and even post-purchase repairs.

During the ideation and experimentation phases, finding the solution to the identified problems was the goal. The solution proposals were sketched up in the ideation phase of the one-week sprint, then their testing with the personas was carried out in the experimentation phase. We have identified the solution options and have evaluated them for the benefits and resources needed. Rapid prototyping or other demonstrative tools helped us to demonstrate those for both consumers and bank executives. This gave us valuable feedback.

Finally, in the evolution phase we defined the possible MVP functionality and the entry strategy. In the upcoming two sections, we focus on customer journey mapping and analysis and the usage of personas, as our key methodological elements in this research.

\subsection{Using personas}

In Bank1 it was easy to identify personas. Just considering customer segments and demographic properties, we were able to generate four personas (Figure 3):

- Balázs, fresh out of university, who wants to move out from his parents' house. He has no savings, and is at the beginning of his career;

- Bence and Csilla, a young couple, with a baby on its way. They want to find a house for their growing family; they have some savings and a decent income;

- Dénes and Edit, an older couple, their children have all flown out of the nest, and they are now searching for a real estate investment;

- Ferenc, an investor, who buys real estate for business. 


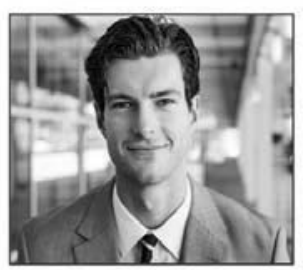

\section{BALÁZS}

Age: 30

Work: Consulting

Marital Status: Single

Kids: None

\section{Goals: \\ - Seeking for 1 st real estate investment \\ - Flat (second hand or new)}

\section{Financing: \\ - Stable, growing income \\ - Parents \\ - Private funds}

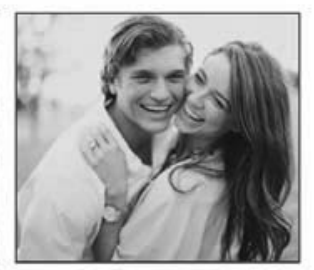

BENCE and CSILLA Age: 29 and 25

Work: Both (Analyst and

Financial Associate)

Marital Status: In relationship Kids: Expecting
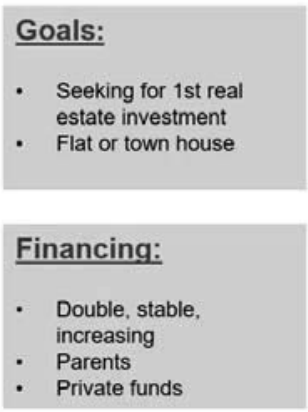

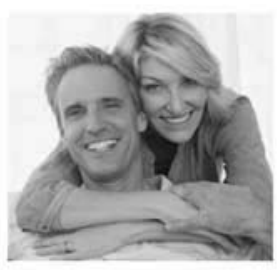

DÉNES and EDIT

Age: 52 and 49

Work: Senior Accountant and Brand Specialist

Marital Status: Married Kids: 2
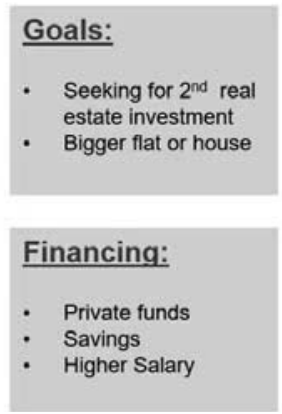

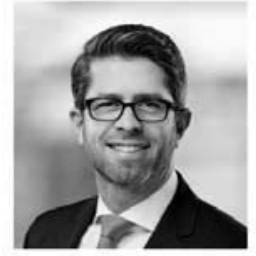

FERENC

Age: 54

Work: Businessman

Marital Status: Single

Kids: None

Figure 3. Personas of Bank1

Source: authors

The personas are based on the interviews. Of course, they are just generalized "avatars" of the customer segments we found. They are not derived from the bank's CRM system, and they can only be connected to the real-estate issues. In the case of Bank1, we identified that personas are useful in considering the goals, desires, and limitations of customers and users in order to help guide decisions about a service, product or solution to any need. These personas are easy to understand and easy to feel their challenges even without the customer journey. It is worth creating them, as due to their names and preferences it is much easier to emotionally connect with them.

In Bank2, the personas were companies, named after their owners. We have generated three personas (Figure 4):

- Balázs's Garage: a micro firm, with two employees. Its financial state is uncertain, but growing. The company has been operational for less than 2 years.

- Mónika's Store: a local restaurant with 10 employees. Its financial state is volatile; the company has been operating for 4 years. 


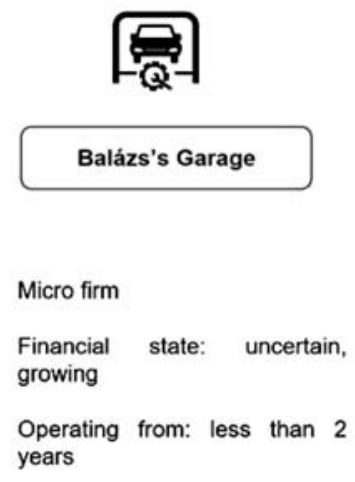

Source: authors

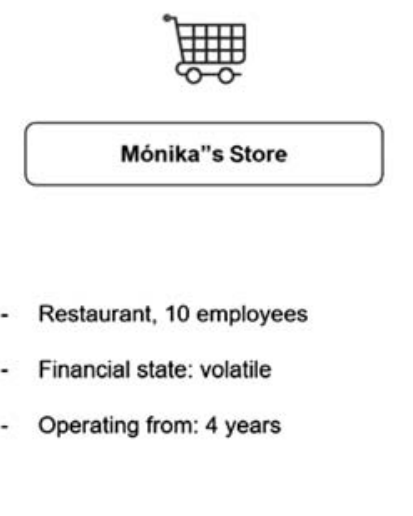

Figure 4. Personas of Bank2

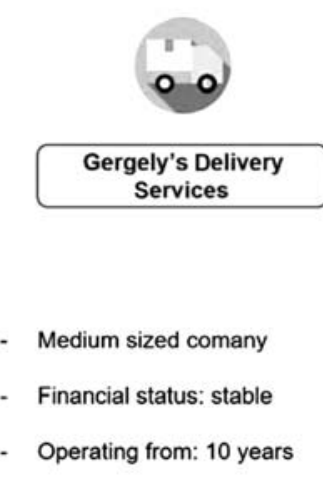

Medium sized comany

- Operating from: 10 years

- Gergely's Delivery Services: An SME turning into a stable medium sized company. Its financial status is stable; the company has been in the field for 10 years.

Personas are said to be cognitively compelling because they put a human face on otherwise abstract data about customers. In the case of Bank2, we felt that speaking about a company has no personal feeling at all, that is why we named them after their owners. But speaking about the owner does not reflect completely the company itself. In this case, we found that using a persona does not add that much value to the project as it should.

\subsection{Using customer journey mapping and analysis}

The usage of customer journey mapping and analysis in Bank1 had two phases: first, identifying the general customer journey all customers face when they have any kind of real estate related issue. This customer journey is easy to form from the general one mentioned in section 2.1. We have identified that the Customer Journey for real estate related issues is the following:

- Awareness: The customers want to find a property.

- Discovery: Customers are searching for a property.

- Interest: Customers find more properties, they check them, and prioritize between possibilities.

- Selection: Customers are making a choice, and most of the time they need professional help for financing or with legal aspects. 
- Purchase: Having decided to continue with the purchase, they are now moving to execute the transaction itself.

- Actions after purchase: This includes moving in, repairing, purchasing of furniture or any equipment. In the long run, we can think about paying back the loan at this point, although that will last for decades in the future.

After identifying the steps of the Customer Journey, we have combined it with the personas. We have to capture their touchpoints, feelings and their problems (moment of truth). The complete customer journey for the young professional persona (Balázs) is shown in Figure 5.

Based on all customer journeys of the personas, we were able to identify that the bank should not be involved in financial issues only, because customers face a number of other challenges. They lack financial knowledge, and when they think about buying real estate, it is late to start any kind of savings. Processes are paper-based and time consuming, and it is hard to find a reliable real estate agent with relevant advertisements. Furthermore, it is hard to find reliable tradesmen for actions after the purchase.

As solutions, we have identified and created to following:

- An education and awareness portal or game, for the younger generation, or even for the whole family. This game teaches the importance of savings, mortgages, bank accounts, etc. in a customer friendly way. There should be well defined life events with their financial challenges in the system, so customers can understand the importance of financial awareness.

- The bank should partner with a real estate agency and both sides should cross-sell the others' services.

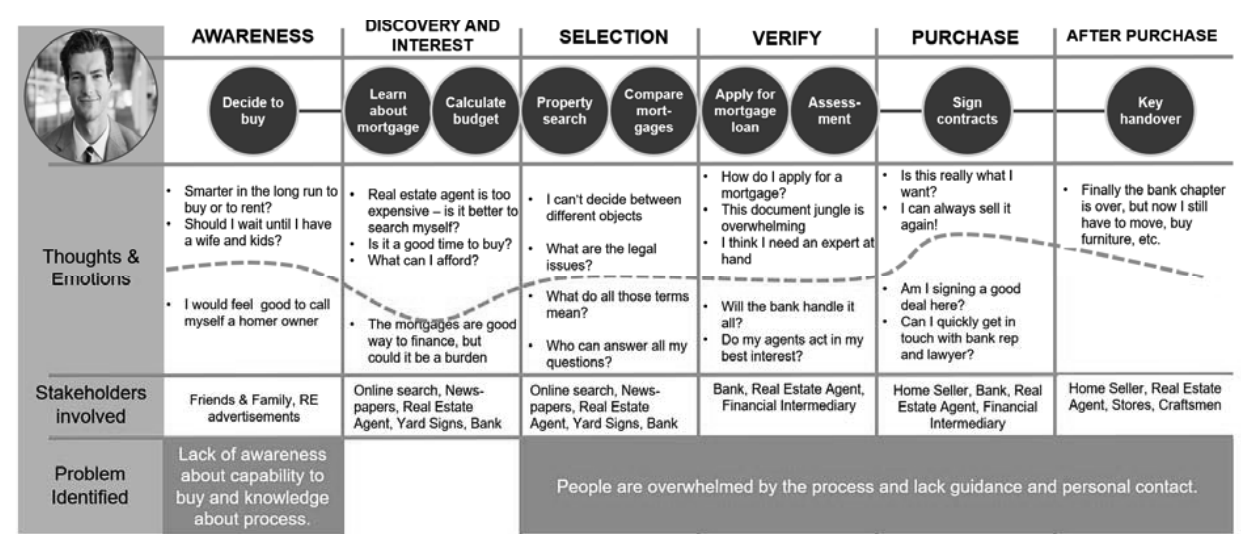

Figure 5. Customer journey for a persona in Bank1

Source: authors 
- The bank should create a portal and a mobile application that can guide the customer through the whole customer journey. In this application, the partner real estate agency's advertisements can be browsed, if the customer selects a property, they can have a mortgage offer for it, and the contract for the mortgage can also be signed online. After the purchase, the application can serve the customer as the "Yellow Pages for Tradesmen", and the customer should not handle money at all, since the bank can transfer the price of furniture or works to the tradesmen.

Both the customers and the representatives of Bank1 found these solutions interesting, although the bank thought that the last idea is way too complex and could only be developed in smaller functional fragments.

In Bank2, creating the customer journey was a much harder task. The main question of Bank2 was "What to offer to SMEs?", which is basically a product development issue. So, how can we identify a general customer journey? We can say that the customer journey is how SMEs interact with their bank, or - as a more general thought - we can say that it is the lifecycle of a company, since different lifecycle elements require different services from banks.

During our research, we tried to focus on three areas for companies: how do they gather information, how do they interact with the bank, and whether their connection with the bank could be extended with any other services. This is less like a customer journey, but the intensity of the connection between the company and the bank is increasing in this model.

We have identified that the main challenges companies face (and not only with their banks) are the following:

- they cannot find relevant bank information online, therefore have to go to the branch;

- they need financial education (too many products, little knowledge);

- banking processes are paper-based and inflexible;

- they have cash-flow problems during the months;

- they need office space and a webpage;

- they need legal and accounting advice and services;

- they are searching for alternate financing opportunities.

When we think about the solutions, we do not have to address all the challenges mentioned. The goal of the ideation phase in the One Week Sprint is to come up with as many solutions as possible, but limit them later based on feasibility and affordability. In the case of Bank2, we were unable to plan a product with a mockup or detailed functionality, but we have identified future opportunities for the bank, such as: 
- partner up with accounting and tax specialist companies and cross-sell their products (this can be a functionality of a virtual assistant);

- create an educating platform for company users;

- create omnichannel, digital processes to avoid paperwork;

- partner up with startups for crowdfunding opportunities and P2P loans with social scoring.

The mentioned improvement opportunities were interesting for the customers (companies) and the bank too. Feedback showed that the companies would be interested in any solution, if it makes their life easier and the processes faster at an affordable price.

\section{CONCLUSIONS}

In this paper we gave an overview of the challenges of the banking industry in general and in Hungary in particular. We introduced design thinking, which can be a solution to enhance customer experience and provide answers to the challenges. We gave a general overview of customer journey mapping and the usage of personas, and demonstrated the added value and our practical experiences via two cases from the banking industry.

In Bank1, we were able to gain enough information and customer data from the relevant area. In the customer journey, we were able to identify the sequence of actions with the feelings and thoughts of the customers. We identified possible new touchpoints between the customers and the bank, like helping customers with the search for real estate, conscious purchases, and even post-purchase repairs.

In Bank2, we also aimed to focus on the customer journey and personas, but the practice has shown that companies are much harder to be defined as personas, since the question is rather where the company itself is in its life cycle. In addition, as the banking objective was innovative product development, which was not focused enough, we could not build on a specific area along the customer journey, and needed to rely solely on the overall life cycle of the companies.

We believe that this project was an important learning phase for us. We were able to understand the importance of the discovery phase, where the goal is to gain a better understanding of the industry and the customers as well. If we do not know the costumers' main issues, we are unable to use one of the most important parts of design thinking, which is empathy. Without empathy we cannot generate a meaningful customer journey, and the whole project becomes unrealistic.

After this project, we added another point to the One Week Sprint, the "zeroest" phase, which is preparation. We felt we needed this as an enhancement of 
discovery, if the research area cannot be understood in one day. Since the mentors always have to prepare for a design thinking project, it is their duty to identify if the research teams may need more time and materials for the discovery.

In general we can say that the main benefits of using customer journey mapping and analysis with personas are better customer experience and greater efficiency. These tools can help the analyst/designer to see everything from the customers' point of view and identify their "pain points." By identifying the main stages and touchpoints, organizations may offer information, messages and services when customers really need them. Unmet needs of customers may lead to innovative new products or services of the organization. All of these may generate more satisfied customers, lower costs and increasing revenues. We found that all these benefits are easier to realize with human personas, and much harder with companies. The proper usage of personas and customer journey mapping and analysis may be a fruitful avenue for future research.

\section{REFERENCES}

Blakstad, S. - Allen, R. (2016): Let's Not Build a Bank: New Standard Models for Banking. https:// www.linkedin.com/pulse/lets-build-bank-new-standard-models-banking-sofie-blakstad/, accessed 25/07/2019.

Boms, S. (2018): US Way behind the Curve in Open Banking.” American Banker, September 21, 2018. https://www.americanbanker.com/opinion/us-way-behind-the-curve-on-open-banking, accessed 25/07/2019.

Carroll, J. M., ed. (1995): Scenario-Based Design: Envisioning Work and Technology in System Development. Wiley.

Chapman, C. N. - Milham, R (2006): The Personas'New Clothes. San Francisco: Human Factors and Ergonomics Society.

Cooper, A. (1999): The Inmates are Running the Asylum. Sams.

Deloitte (2019): 2019 Banking and Capital Markets Outlook. https://www2.deloitte.com/content/ dam/Deloitte/global/Documents/Financial-Services/gx-fsi-dcfs-2019-banking-cap-marketsoutlook.pdf, accessed 25/07/2019.

Fehér, P. - Varga, K. (2017a): A vevőé az irányítás [The Consumer Has Control]. Computerworld Számítástechnika 48(1): 20.

Fehér, P. - Varga, K. (2017b): A digitális átalakulás lehetőségei a magyar bankszektorban [The Potential for Digital Transformation in the Hungarian Banking Sector]. Computerworld Számítástechnika 48(5): 20-23.

Ghose, R. - Dave, S. - Shirvalkar, A. - Horowitz, K. - Tian, Y. - Levin, J. - Ho, S. (2016): Digital Disruption - How FinTech is Forcing Banking to a Tipping Point. City GPS

HM Government (2017): Customer Journey Mapping - A Guide for Practitioners. http://webarchive. nationalarchives.gov.uk/+/http:/www.cabinetoffice.gov.uk/media/123970/journey_mapping1 . pdf, accessed 25/07/2019.

Köhler, T. (2001): Methoden der Analyse computervermittelter Kommunikation: ein kritischer Überblick; In: Frindte, W. - Köhler, T. - Marquet, P. - Nissen, E. (eds): IN-TELE 99 - InternetBased Teaching and Learning 99. Frankfurt am Main: Peter Lang Verlag. 
Lawton, A. (2016): Customer Journey Mapping: A Valuable Strategic Tool in Challenging Times. https:/www.mastercardadvisors.com/content/dam/advisors/en-us/CompendiumAssets/PDF/ customerJourneyMapping.pdf, accessed 25/07/2019.

Oracle Webcenter (2013): The Digital Customer Journey: How to Build an Online Experience that Drives Sales and Loyalty. http://www.oracle.com/us/products/middleware/digital-customerjourney-wp-2028079.pdf, accessed 25/07/2019.

Rönkkö, K. (2005): An Empirical Study Demonstrating How Different Design Constraints, Project Organization, and Contexts Limited the Utility of Personas. Hawaii International Conference on System Sciences (HICSS), Waikoloa, HI, USA.

Ross, A. - Srinivas, V. (2018): Accelerating Digital Transformation in Banking: Findings from the Global Consumer Survey on Digital Banking, Deloitte Insights. https://www2.deloitte.com/ insights/us/en/industry/financial-services/digital-transformation-in-banking-global-customersurvey.html, accessed 25/07/2019.

SAP Hybrids (2016): The Customer Journey - A Handbook for Meaningful (and Profitable) Engagement.https://www.hybris.com/medias/sys_master/root/h7f/hee/8812826066974/saphybriscustomer-journey.pdf, accessed 25/07/2019.

Software AG (2015): Customer Journey Mapping with ARIS. https://www.ariscommunity.com/ system/files/ARIS_customer_journey_mapping.pdf, accessed 25/07/2019

Temenos Group (2018): Customer Demand Leads the Way to Digitalized Banking in Asia-Pacific. https://www.temenos.com/en/news-and-events/news/2018/july/customer-demand-leads-theway-to-digitalized-banking-in-asia-pacific/, accessed 25/07/2019.

Touchpoint Dashboard (2014): A Guide to Customer Journey Mapping. http://www. touchpointdashboard.com/wp-content/uploads/2014/03/TPD-Mapping-Guide-2014.pdf, accessed 25/07/2019.

Open Access. This is an open-access article distributed under the terms of the Creative Commons Attribution 4.0 International License (https://creativecommons.org/licenses/ by/4.0), which permits unrestricted use, distribution, and reproduction in any medium, provided the original author and source are credited, a link to the CC License is provided, and changes - if any - are indicated. (SID_1) 